\title{
Evaluation of the Effects of an Intervention Intended to Optimize the Sleep Environment Among the Elderly: An Exploratory Study
}

This article was published in the following Dove Press journal:

Clinical Interventions in Aging

\author{
Sophie Desjardins $\mathbb{D}^{\prime}$ \\ Sylvie Lapierre' \\ Helen-Maria Vasiliadis ${ }^{2}$ \\ Carol Hudon ${ }^{3}$ \\ 'Department of Psychology, Université du \\ Québec à Trois-Rivières, Trois-Rivières, \\ Québec, Canada; ${ }^{2}$ Faculty of Medicine and \\ Health Sciences, Université de Sherbrooke, \\ Longueuil, Québec, Canada; ${ }^{3}$ School of \\ Psychology, Université Laval, Québec, \\ Québec, Canada
}

Purpose: The objective of this exploratory study was to evaluate the effects of a brief intervention intended to optimize the sleep environment in older people living in the community and to examine the way these effects change over time.

Methods: The sample was made up of 44 participants (19 men and 25 women) aged 65-85 years, with a mean age of 71.4. The intervention consisted in a group training session that covered the reasons for and ways to ("why" and "how") optimize a sleep environment. It comprises six themes: air quality and odors, luminosity, noises and sounds, comfort of the mattress, comfort of the pillow, and temperature. Participants completed a set of questionnaires before the intervention, and one month and four months later.

Results: Four months after the intervention, the replies to the questionnaires showed that the participants experienced reduced severity of insomnia, sleep latency and anxiety. The subjective quality of the participants' sleep along with their sleep efficacy also increased significantly during the same period.

Conclusion: A brief intervention intended to optimize the sleep environment appears promising as an addition or alternative to the two other sleep improvement options generally offered to older people: medication and cognitive behavioral therapy.

Keywords: bedroom, insomnia, sleep efficiency, sleep latency, sleep quality, sleep treatment

\section{Introduction}

Sleep problems are quite common in adults aged 65 years and over; most people in this age group describe their sleep as light and fragmented. ${ }^{1,2}$ A review of the literature on the subject found that $15 \%$ to $45 \%$ of non-institutionalized elderly people had difficulty falling asleep, that $20 \%$ to $65 \%$ of them had sleep disturbances, and that $15 \%$ to $54 \%$ woke up too early in the morning, whereas $10 \%$ had nonrestorative sleep. ${ }^{3}$ In Canada, a nationally representative, cross-sectional survey conducted in 2014-2015 found that 22.2\% of people aged 65 and over reported nocturnal symptoms of insomnia (ie, having trouble falling asleep or staying asleep), and $93 \%$ of them had experienced the symptoms for one year or longer. ${ }^{4}$

These sleep disturbances cause several negative consequences including: daytime sleepiness, fatigue, and cognitive deficits, ${ }^{5-8}$ increased risks of falls and fractures, ${ }^{1,2,9-13}$ higher rate of accidents and mortality, ${ }^{14,15}$ pain, ${ }^{16}$ lower life satisfaction, ${ }^{17}$ poorer quality of life and worse physical and mental health. ${ }^{7,18-22}$

Older people who want to improve their sleep are generally offered two options: the most frequent treatment is pharmacological. From $16 \%$ to $33 \%$ of
Correspondence: Sophie Desjardins Department of Psychology, Université du Québec à Trois-Rivières, C.P. 500, TroisRivières, Québec, G9A 5H7, Canada,

Tel + I 819376501 I

Fax + 8193765195

Email sophie.desjardins@uqtr.ca 
noninstitutionalized older people consume benzodiazepines (BZD). ${ }^{23-25}$ In Québec (Canada), elderly individuals consume these drugs on average more than 200 days per year. ${ }^{25}$ Nonetheless, BZD and other hypnotic drugs are among the drugs that should not be prescribed to seniors, without consideration of duration of use, due to the important risks they pose and to their minimal efficacy in treating insomnia. ${ }^{26}$ The second option is psychotherapeutic: cognitive behavioral therapy. Although the long-term efficacy of this therapy has been demonstrated, it requires a large number of sessions and considerable effort on the part of the elderly client. $^{27}$ Further, it takes considerable time for its beneficial effects to be felt. ${ }^{28}$ In addition to the economic barriers that hinder access to psychotherapy, ${ }^{29}$ seniors are typically reluctant to seek help for mental health problems, and they tend to underuse the services offered. ${ }^{30,31}$ There is also a third option worth exploring, that of optimizing one's sleep environment, which entails modifying the bedroom to make it maximally conducive to quality sleep.

A study involving about 600 community-dwelling older people ${ }^{32}$ found that a large proportion of the sample did not have an optimal sleep environment. These participants initially took part in the longitudinal Québec Survey on Seniors' Health (Enquête sur la santé des aînés), which addressed a representative sample $(n=2798)$ of elderly persons living in the community. ${ }^{33}$ The latter were contacted again by mail and invited to fill out questionnaires on sleep environment characteristics and sleep quality. Among other results, nearly half of the participants claimed that their pillow was not very comfortable. In addition, $30 \%$ of the sample reported that they did not sleep in a completely silent bedroom at night. The researchers determined that the probability of experiencing mild to severe insomnia was twice as high when the pillow was rated from moderately comfortable to very uncomfortable, and when the bedroom was rated as not completely quiet at night. Although this cross-sectional study did not make it possible to establish causal links between sleep environment and insomnia, it affirmed the hypothesis that simple, minor, and easily managed changes to the bedroom can promote sleep, and benefit the physical and psychological health of the elderly. A vast literature review supports the idea that basic environmental changes such as mitigating noise and light in a hospital setting can improve patients' sleep significantly. ${ }^{34}$
An in-depth review of the prerequisites for an optimal sleep environment was published quite recently. ${ }^{35}$ The authors examined the impact of noise, temperature, light and air quality on sleep, and made recommendations about each of these parameters in the bedroom environment to facilitate optimal sleep. Our team drew on these reviews along with the most advanced scientific knowledge to design a brief intervention (a single group training session) to inform community-dwelling older people precisely why and how to optimize their sleep environment. This optimization of the sleep environment was broken down into themes inspired by the studies of Desaulniers et $\mathrm{al}^{32}$ and Caddick et $\mathrm{al}^{35}$ : air quality and odors, luminosity, noises and sounds, comfort of the mattress, comfort of the pillow, and temperature. A literature review specifically related to these themes notably shed light on the efficacy of additional strategies such as use of lavender essential oil, ${ }^{36-40}$ listening to music before going to bed, ${ }^{41-44}$ and taking a bath or footbath before bedtime. ${ }^{45}$

The main goal of the present exploratory study is to evaluate the effects of this brief intervention and to verify if they changed over time. This research therefore answers the recent call by sleep experts for studies that evaluate the effects of strategies that: 1) are intended to improve sleep in nonclinical populations, 2) do not require intervention from a clinician, 3) can be accessed easily by individuals who are not likely to seek help, 4) are inexpensive, and 5) are attractive and commonsensical. ${ }^{46}$

Given the potential two-way links between sleep, anxiety, depression, quality of life, life satisfaction, and pain, the following hypotheses were formulated: compared with the pretest, the quality of sleep, quality of life and life satisfaction will improve one month after the intervention, whereas symptoms of insomnia, anxiety and depression will decrease, as well as pain. Four months after the intervention there will be further improvement compared with the assessment done one month after the intervention.

\section{Methods}

\section{Procedure}

The Research ethics committee of the Université du Québec à Trois-Rivières (ethics approval number: CER19-255-07.01) approved this research, which was in accordance with the Declaration of Helsinki. Written informed consent was obtained by the participants prior to study commencement. To participate in the study, participants had to be aged 65 or over and live in the community (as 
opposed to living in institutional settings). They should also be interested in taking training intended to optimize their sleep environment. The exclusion criteria were: receiving professional psychological help, taking nonstabilized medication or having poor cognitive functioning [rating below 20 on the Mini-Mental State Examination (MMSE)]. ${ }^{47}$ Problems with sleep, anxiety and depression did not constitute criteria of inclusion or exclusion, but rather variables of interest. Participants were recruited through an article in a local newspaper that discussed the intervention offered and the research project, through an email sent to retiree associations, and through posters in medical clinics, pharmacies and residences for independent older people.

First, potential participants were met with individually. During this meeting, the individuals received an information sheet and a consent form, and could obtain answers to their questions about the project. The participants' cognitive functioning was then evaluated using the MMSE, and they completed the questionnaires described below. About one month later, the participants attended the group training session. They completed all the questionnaires again one month and four months after the intervention.

\section{Intervention}

The training, inspired by the most up-to-date scientific knowledge, lasted approximately 90 minutes. It covered the reasons for and ways to ("why" and "how") optimize a sleep environment, and comprised six themes. Table 1 presents the themes and components of the training. The training was provided at the Université du Québec à TroisRivières, the first time to a group of 31 participants and two weeks later to 17 participants who were not available during the first session. Participants each received \$20 to cover their travel expenses and parking costs. Before the start of the session, a document containing the slides presented during the training was given to the participants on which they could take notes. These documents also enabled them to retain the information provided and to refer to it as needed.

\section{Participants}

The initial sample consisted of 48 people, all of whom met the cognitive requirements (MMSE range $=29-30$ ). However, four participants withdrew from the project (illness, $\mathrm{n}=2$; lack of time, $\mathrm{n}=1$ ) or did not fully complete the questionnaire $(n=1)$. Therefore, the final sample included 44 persons aged 65 to 85 (mean $=71.4$; $\mathrm{SD}=$
4.8). Table 2 presents their sociodemographic characteristics. Using chi-squares for categorical variables and t tests for continuous variables, the researchers compared the 4 participants who did not participate in the entire study with the 44 others who participated in the entire study, for the set of sociodemographic characteristics and for all of the variables measured in the variables measured in the pretest. No significant difference was observed between these participants and the rest of the sample population at the $5 \%$ level.

\section{Questionnaires}

The Insomnia Severity Index (ISI) ${ }^{48}$ is a 7-item self-report questionnaire that was specifically designed to assess the severity and effects of insomnia over the past two weeks. The first three items evaluate the severity of sleep-onset (initial), sleep maintenance (middle), and early morning awakening (terminal); the last four items capture satisfaction with current sleep pattern, interference with daily functioning, noticeability of impairment attributed to the sleep problem, and level of distress caused by the sleep problem. All items are rated using a five-point Likert scale; from "none" to "very severe" for items 1 to 3 ; from "very satisfied" to "very dissatisfied" for item 4; and from "not at all" to "very much" for items 5 to 7 . The total score ranges between 0 and 28 , where $0-7$ indicates absence of insomnia, 8-14 indicates subthreshold insomnia, 15-21 indicates moderate insomnia, and 22-28 indicates severe insomnia. ${ }^{48}$ The ISI has good internal consistency (Cronbach's $\alpha$ ranging from 0.74 to 0.91 ), is sensitive to change, and has demonstrated good convergent, concurrent, and content validity. ${ }^{49,50}$

The Pittsburgh Sleep Quality Index (PSQI) ${ }^{51}$ is the most widely used scale for evaluating subjective sleep quality and disturbances over the previous month. It contains questions such as: "During the past month, how many hours of actual sleep did you get at night (this may be different than the number of hours you spend in bed)?", "During the past month, how often have you taken medicine (prescribed or 'over the counter') to help you sleep?", and "During the past month, how often have you had trouble staying awake while driving, eating meals, or engaging in social activity?" In scoring this 19 self-report, seven component scores are derived (subjective sleep quality, sleep latency, sleep duration, sleep efficiency, sleep disturbances, use of sleep medication, and daytime dysfunction), each scored 0 (no difficulty) to 3 (severe difficulty). Concerning the "sleep duration" component, 
Table I Themes and Components of the Brief Intervention on Optimization of the Sleep Environment

\begin{tabular}{|c|c|c|}
\hline Themes & Information Shared & Optimization Proposals \\
\hline $\begin{array}{l}\text { Air quality } \\
\text { and odors }\end{array}$ & $\begin{array}{l}\text { The sleep environment is the most polluted place in a home. It contains } \\
\text { chemical contaminants, dust mites, fungi and bacteria. } \\
\text { Under the sheets, many factors contribute to poor air quality: high level } \\
\text { of humidity, high temperature, low volatility, high molecular weight of } \\
\text { pollutants, and poor ventilation. } \\
\text { Good air quality and adequate ventilation are important to ensure quality } \\
\text { sleep. }\end{array}$ & $\begin{array}{l}\text { - Aerate as much as possible } \\
\text { - Vacuum the floor and the mattress } \\
\text { - Use an air purifier with a HEPA filter } \\
\text { - Wash the bedding frequently in hot water } \\
\text { - Use protective covers on the pillow and mattress } \\
\text { - Replace your pillow and mattress from time to time } \\
\text { Supplement: The positive effects of lavender essential oil on } \\
\text { sleep have been scientifically demonstrated in most people. }\end{array}$ \\
\hline Luminosity & $\begin{array}{l}\text { Human beings have an internal clock called the circadian rhythm, which } \\
\text { lasts approximately } 24 \text { hours. The most powerful synchronizer of this } \\
\text { clock is light. } \\
\text { Melatonin, also known as the sleep hormone, is a sleep aid. It is strongly } \\
\text { associated with lower body temperature, decreased vigilance and } \\
\text { performance, and a heightened state of fatigue. It promotes sleep onset. } \\
\text { Exposure to typical indoor lighting before bedtime delays the secretion of } \\
\text { melatonin by about } 90 \text { minutes. } \\
\text { Exposure to lighting as weak as } 5 \text { lux during the night is sufficient to act } \\
\text { on melatonin and modify sleep architecture. }\end{array}$ & $\begin{array}{l}\text { - Dim the light in the evening and avoid all sources of blue light } \\
\text { (TVs, computer screens) } \\
\text { - Install roller blinds and opaque curtains } \\
\text { - Sleep with a blindfold (sleep mask) } \\
\text { Supplement: It has been scientifically demonstrated that } \\
\text { exposure to a very bright source of light as quickly as possible } \\
\text { after waking up in the morning will reduce awakenings and } \\
\text { increase the quality of sleep during the next night. }\end{array}$ \\
\hline $\begin{array}{l}\text { Noises and } \\
\text { sounds }\end{array}$ & $\begin{array}{l}\text { Noises and sounds are processed by the brain even during sleep. } \\
\text { Among the sources of noise pollution that hinder sleep, urban traffic is the } \\
\text { most common. Processing sounds during the night may disrupt sleep cycles } \\
\text { by lengthening the amount of time spent in the stages of light sleep (stages I } \\
\text { and 2) and may consequently reduce time spent in deep sleep (stages } 3 \\
\text { and 4). } \\
\text { Beyond } 10 \text { to } 14 \text { awakenings per hour, sleep would be so fragmented that } \\
\text { upon waking up in the morning, seniors would be more likely to feel pain. }\end{array}$ & $\begin{array}{l}\text { - Use earplugs } \\
\text { - Turn on a machine that emits a constant noise (eg, fan) to } \\
\text { mask intermittent noises } \\
\text { - Replace the windows } \\
\text { - Sleep in a room farthest from sources of noise } \\
\text { Supplement: It has been scientifically demonstrated that } \\
\text { listening to } 20 \text { to } 45 \text { minutes of relaxing music before going to } \\
\text { bed favors the ability to fall asleep and improves the quality of } \\
\text { sleep after about three weeks of daily practice. }\end{array}$ \\
\hline $\begin{array}{l}\text { Comfort of } \\
\text { the mattress }\end{array}$ & $\begin{array}{l}\text { The role of the mattress is to support the spinal column in a similar position to } \\
\text { the vertical position, to distribute the weight load equitably and minimize } \\
\text { biomechanical stress on some body structures. } \\
\text { A comfortable mattress should facilitate necessary changes in posture to avoid } \\
\text { overloading the soft tissue and preventing muscle stiffness that can affect the } \\
\text { quality of sleep. } \\
\text { A moderately firm mattress is recommended. } \\
\text { The use of a new, well adapted mattress can alleviate pain significantly and } \\
\text { enhance sleep quality. These gains persist six months later, and improvement } \\
\text { appears to continue over time. }\end{array}$ & $\begin{array}{l}\text { - Procure a mattress that is well adapted to your preferences } \\
\text { and particular needs }\end{array}$ \\
\hline $\begin{array}{l}\text { Comfort of } \\
\text { the pillow }\end{array}$ & $\begin{array}{l}\text { The main role of the pillow is to support the neck bones in an optimal } \\
\text { position to reduce biomechanical stress on the spinal column structure. } \\
\text { Feather pillows are to be avoided. These pillows were rated lowest in } \\
\text { terms of comfort (neck stiffness), quality of sleep and temperature } \\
\text { regulation among all types of pillows. } \\
\text { When evaluating three thicknesses of latex pillows ( } 5,10 \text { and } 14 \mathrm{~cm} \text { ), the } \\
10 \mathrm{~cm} \text { version was considered the most comfortable. It also maximally } \\
\text { promotes muscle relaxation. } \\
\text { Nonetheless, the current state of knowledge does not allow us to } \\
\text { precisely affirm which characteristics of a pillow favor sleep in different } \\
\text { populations. The choice of a pillow is therefore largely dictated by } \\
\text { personal preference. }\end{array}$ & $\begin{array}{l}\text { - Procure a pillow that is well adapted to your preferences and } \\
\text { particular needs }\end{array}$ \\
\hline
\end{tabular}

(Continued) 
Table I (Continued).

\begin{tabular}{|c|c|c|}
\hline Themes & Information Shared & Optimization Proposals \\
\hline Temperature & $\begin{array}{l}\text { During both daytime and nighttime, internal temperature and skin } \\
\text { temperature interact to attain a balance between heat loss and heat } \\
\text { production. } \\
\text { Moderate exposure to heat or cold during the night has a negative impact } \\
\text { on sleep quality, particularly in older people. } \\
\text { During sleep, several factors interact: internal body temperature, skin } \\
\text { temperature, ambient temperature, ventilation, humidity rates, night } \\
\text { clothes, and bedding. } \\
\text { A sleep environment with a temperature between } 17^{\circ} \mathrm{C} \text { and } 28^{\circ} \mathrm{C} \text { and } \\
\text { a humidity rate between } 40 \% \text { and } 60 \% \text { can generally create a microclimate } \\
\text { (under the sheets) of } 34^{\circ} \mathrm{C} \text { to } 36^{\circ} \mathrm{C} \text {, which favors sleep, given the normal } \\
\text { body temperature of } 36.6^{\circ} \mathrm{C} \text {. } \\
\text { Sleep is disturbed more by heat than by cold. }\end{array}$ & $\begin{array}{l}\text { - Choose sleepwear and bedding that is easily adaptable during } \\
\text { the night } \\
\text { - Use a fan or air conditioner } \\
\text { - Install programmable thermostats } \\
\text { - Use a humidifier or dehumidifier } \\
\text { Supplement: Scientific studies have shown that taking a hot bath } \\
90 \text { to I } 20 \text { minutes before going to bed benefits sleep. A foot } \\
\text { bath before bedtime also has positive effects. }\end{array}$ \\
\hline
\end{tabular}

for example, a duration longer than 7 hours is rated 0 , between 6 and 7 hours is rated 1, between 5 and 6 hours is rated 2 and below 5 hours is rated 3 . The total score ranges from 0 to 21. A global PSQI score greater than 5 yielded a diagnostic sensitivity of $89.6 \%$ and specificity of $86.5 \%$ in distinguishing good and poor sleepers. The measures of internal homogeneity, test-retest reliability, and validity are acceptable. ${ }^{51}$ The French-language version of the PSQI presents good internal consistency $(\alpha=0.88) .^{52}$

The Geriatric Anxiety Inventory (GAI) ${ }^{53}$ is a 20 -item questionnaire that evaluates the presence of anxiety symptoms in the previous week. Each item can be scored as 0 (symptom not present) or 1 (symptom present). The total score therefore varies from 0 to 20 . The GAI emphasizes cognitive manifestations of anxiety rather than somatic symptoms, which may be confounded with physical health problems in older individuals. The cutoff of $8 / 9$ is recommended for identifying an anxiety disorder, has $69.6 \%$ sensitivity, and $100 \%$ specificity. ${ }^{54}$ The French-Canadian version of the GAI presents high internal consistency $(\alpha=0.94)$, adequate convergent validity $(r=0.50$ to 0.86 with instruments known to evaluate constructs similar to the GAI or related to anxiety), good test-retest reliability $(r=0.89)$, and a single-factor structure. ${ }^{55}$

The Geriatric Depression Scale (GDS) ${ }^{56}$ has also been specifically designed to evaluate the intensity of symptoms of depression in older individuals by placing less weight on somatic symptoms (such as weight loss) that often accompany aging. Each of its 30 items can be scored as 0 (symptom not present) or 1 (symptom present). A score of 0 to 9 is considered normal, a score of 10 to 20 indicates a mild depressed state, and a score of 21 to 30 suggests the presence of a moderate or serious depressive state. The reliability and validity of the original version of the GDS have been clearly established. $^{57}$ The French-Canadian version of the GDS presents coefficients of internal consistency of 0.84 and 0.89 , along with test-retest coefficients of 0.70 and $0.83 .^{58,59}$

The World Health Organization Quality of Life ScaleBREF (WHOQOL-BREF) ${ }^{60}$ is a self-report generic quality of life (QoL) inventory that was developed as a short version of the WHOQOL-100. It consists of 26 items rated on a 5 -point Likert scale $(1=$ not at all/very dissatisfied/very poor to $5=$ completely/very satisfied/very good). The first two items are treated separately from the others. They evaluate overall perception of quality of life and overall perception of health. The remaining 24 items assess the four domains of the QoL: physical health (7 items), psychological (6 items), social relationships (3 items), and environment ( 8 items). Following the World Health Organization scoring guide, the raw scores of each domain are transformed into scores ranging from 4 to 20 , whereas the first two items range from 1 to 5 . There is no cutoff value. Higher scores indicate better QoL. The WHOQOL-BREF has proven internal consistency reliability, content, and discriminant validity. ${ }^{61}$ The reliability (Cronbach's alpha coefficients all above 0.65 ) and the divergent and convergent validity of the Frenchlanguage version of the instrument have also been shown to be satisfactory. ${ }^{62}$

The Satisfaction with Life Scale (SWLS) ${ }^{63}$ is a fiveitem self-report questionnaire that measures general life satisfaction. Items are rated on a 7-point Likert scale, from 
Table 2 Socio-Demographic Characteristics of the Participants

\begin{tabular}{|c|c|c|}
\hline Characteristics & $\begin{array}{l}\text { Frequency } \\
\text { (n) }\end{array}$ & $\begin{array}{l}\text { Percentage } \\
\text { (\%) }\end{array}$ \\
\hline \multicolumn{3}{|l|}{ Gender } \\
\hline Male & 19 & 43.2 \\
\hline Female & 25 & 56.8 \\
\hline \multicolumn{3}{|l|}{ Marital status } \\
\hline Married and living as a couple & 21 & 47.7 \\
\hline Living as a couple but not married & 8 & 18.2 \\
\hline Divorced and living alone & 7 & 15.9 \\
\hline Widowed and living alone & 3 & 6.8 \\
\hline Single but previously lived as a couple & 4 & 9.1 \\
\hline Single and never lived as a couple & I & 2.3 \\
\hline \multicolumn{3}{|l|}{ Education } \\
\hline Primary & I & 2.3 \\
\hline Secondary & 8 & 18.2 \\
\hline College & 15 & 34.1 \\
\hline University & 20 & 45.5 \\
\hline \multicolumn{3}{|l|}{ Annual income } \\
\hline Less than $\$ 20,000$ & 5 & $1 \mathrm{I} .4$ \\
\hline$\$ 20,000$ to $\$ 29,999$ & 8 & 18.2 \\
\hline$\$ 30,000$ to $\$ 39,999$ & 7 & 15.9 \\
\hline$\$ 40,000$ to $\$ 49,999$ & 11 & 25.0 \\
\hline$\$ 50,000$ and over & 13 & 29.5 \\
\hline \multicolumn{3}{|l|}{ Chronic illness } \\
\hline Yes & 16 & 36.4 \\
\hline No & 28 & 63.6 \\
\hline \multicolumn{3}{|l|}{ Body mass index (BMI) } \\
\hline Underweight & 2 & 4.7 \\
\hline Normal weight & 13 & 30.2 \\
\hline Overweight & 21 & 48.8 \\
\hline Obese & 7 & 16.3 \\
\hline
\end{tabular}

1 (strongly disagree) to 7 (strongly agree). Total scores can be categorized as follows: very high scores (30-35 points), high scores (25-29 points), average scores (20-24 points), slightly below average scores (15-19 points), dissatisfied (10-14 points) and extremely dissatisfied (5-9 points). ${ }^{63}$ The original validation study showed good convergent validity with other assessments of subjective well-being, good test-retest reliability (eg, 4-year temporal stability of $0.54)$, and high internal consistency $(\alpha=0.87){ }^{64}$ The French-Canadian version of the SWLS was validated on a sample of older individuals. Results demonstrated acceptable indices of reliability and validity, together with similar psychometric properties to those of the original version. This version was notably found to possess good internal consistency $(\alpha=0.82){ }^{65}$
The Geriatric Pain Measure (GPM) ${ }^{66}$ is a self-report questionnaire comprising 24 items. It was designed specifically to evaluate the intensity of pain and the effects of this pain on older individuals. Participants answer "Yes" or "No" to 22 items (1 point for "Yes" or 0 points for "No"), whereas the two other items are rated on a scale of 0 to 10 . The total raw score, ranging from 0 to 42 , is then multiplied by 2.38 and converted into scores ranging from 0 to 100. A score below 30 indicates the absence of pain or the presence of light pain, a score ranging from 30 to 69 indicates the presence of moderate pain, whereas a score of 70 or higher indicates the presence of severe pain. This instrument has good concurrent validity $(r=0.63$ with the McGill Pain Questionnaire) and very good internal consistency ( $\alpha=0.94$ ) along with high test-retest reliability ( $\mathrm{r}$ $=0.90$ over a period of 48 to 72 hours). ${ }^{66}$

\section{Statistical Analysis}

First, descriptive analyses were conducted to produce a profile of the participants before they attended the training. One-way repeated measures ANOVA were then conducted to determine whether there were statistically significant differences in questionnaire scores measured at T1 (prior to the intervention), T2 (one-month followup), and T3 (four-month follow-up). In cases where Mauchly's test of sphericity indicated that the assumption of sphericity had been violated, degrees of freedom were corrected using Greenhouse-Geisser estimates of sphericity. Post-hoc tests were completed using the Bonferroni correction. The statistical analyses were performed using IBM SPSS Statistics 27, and statistical significance was considered at $\mathrm{p}<0.05$.

\section{Results}

The ISI scale suggested that before the intervention, 25\% of the participants presented with no insomnia, 36\% with slight insomnia, 32\% with moderate insomnia and 7\% with severe insomnia. The PSQI showed that $70 \%$ of participants were poor sleepers (score higher than 5), whereas the GAI indicated that $36 \%$ of participants were likely to experience an anxiety disorder (score equal to or higher than 8). According to the GDS scale, $20 \%$ of participants had slight symptoms of depression before taking the training. The others had no symptoms of depression. Ninety-five per cent of the participants were satisfied with their life (score equal to or higher than 20) and $77 \%$ reported high or very high satisfaction (score equal to or higher than 25). According to the GPM scale, $73 \%$ of the 
participants felt no pain or only slight pain before the training, 27\% felt moderate pain and no participant was suffering from severe pain.

Table 3 presents the mean scores for each questionnaire for the three measurement times, along with the results of the variance analyses.

Participants' level of insomnia decreased, as illustrated in a reduction of their ISI scores between T1 and T3, and between T2 and T3. This is a very important effect: the partial eta squared was 0.22 . According to Richardson, ${ }^{67}$ Cohen $^{68}$ provided partial eta squared values of 0.0099 , 0.0588 , and 0.1379 as benchmarks for small, medium, and large effect sizes, respectively.

An important effect was also observed in the PSQI, with a significant decrease in sleep problems between $\mathrm{T} 1$ and T3 (partial eta squared $=0.15$ ). Three components of the PSQI explained this result: subjective sleep quality, sleep latency and sleep efficiency. Subjective sleep quality improved substantially between $\mathrm{T} 1$ and $\mathrm{T} 3$ (partial eta squared $=0.16$ ). Sleep latency decreased markedly between $\mathrm{T} 1$ and $\mathrm{T} 2$ and between $\mathrm{T} 2$ and T3 (partial eta squared $=0.15)$. Lastly, sleep efficiency rose significantly between T1 and T3 (partial eta squared $=0.09$ ). No difference was observed between the three measurement times concerning sleep duration, sleep disturbances, use of pharmacological sleep aids and diurnal dysfunction.

Participants' level of anxiety also declined significantly between T1 and T3 and between T2 and T3 (partial eta squared $=0.11$ ).

No difference was noted between the three measure times concerning level of depression, various domains of quality of life, satisfaction with life and pain intensity.

\section{Discussion}

The initial hypotheses were partly affirmed by the results. Compared with their initial measures, four months after the intervention participants experienced a decline in their level of insomnia, sleep latency, and anxiety level, along with improved subjective sleep quality and sleep efficiency. Further, both the level of insomnia and sleep latency declined significantly between the one-month follow-up and the four-month follow-up. However, the one-month

Table 3 Means and Standard Deviations at TI (Prior to the Intervention), T2 (One-Month Follow-Up), and T3 (Four-Month Follow-Up)

\begin{tabular}{|c|c|c|c|c|}
\hline & TI & T2 & T3 & $\boldsymbol{F}$ \\
\hline ISI & II.88 $(6.50)^{\mathrm{a}}$ & $10.82(6.82)^{\mathrm{b}}$ & $8.48(5.27)^{\mathrm{ab}}$ & $1 \mathrm{I} .500 * * *$ \\
\hline Total PSQI score & $7.89(4.23)^{\mathrm{a}}$ & $7.44(4.40)$ & $6.59(3.75)^{\mathrm{a}}$ & $5.527 * *$ \\
\hline \multicolumn{5}{|l|}{ PSQI components } \\
\hline Subjective sleep quality & $1.57(0.89)^{\mathrm{a}}$ & $1.38(0.85)$ & $1.13(0.64)^{\mathrm{a}}$ & $8.186 * * *$ \\
\hline Sleep latency & $1.29(1.18)^{\mathrm{a}}$ & $1.37(1.08)^{b}$ & $0.97(0.79)^{\mathrm{ab}}$ & $6.340 * *$ \\
\hline Sleep duration & $1.07(1.00)$ & $0.90(0.96)$ & $0.83(0.82)$ & 2.401 \\
\hline Sleep efficiency & $1.26(1.08)^{\mathrm{a}}$ & $1.05(1.11)$ & $0.89(1.03)^{\mathrm{a}}$ & $3.506 *$ \\
\hline Sleep disturbances & $1.43(0.50)$ & $1.43(0.50)$ & $1.40(0.54)$ & 0.070 \\
\hline Use of sleeping medication & $1.09(1.34)$ & $1.07(1.28)$ & $\mathrm{I} .07(\mathrm{I} .32)$ & 0.049 \\
\hline Daytime dysfunction & $0.93(0.83)$ & $0.88(0.82)$ & $0.79(0.74)$ & 0.732 \\
\hline GAl & $5.84(6.03)^{\mathrm{a}}$ & $5.34(5.91)^{b}$ & $3.89(4.79)^{\mathrm{ab}}$ & $4.978 * *$ \\
\hline GDS & $5.15(4.31)$ & $5.44(5.14)$ & $5.18(5.54)$ & 0.217 \\
\hline \multicolumn{5}{|l|}{ WHOQOL-BREF domains } \\
\hline Physical health & $15.13(2.61)$ & $15.59(2.33)$ & I5.8I (2.48) & 3.217 \\
\hline Psychological health & $15.38(2.21)$ & $15.60(2.40)$ & $15.66(2.26)$ & 1.101 \\
\hline Social relationships & $14.98(3.22)$ & $15.22(2.78)$ & $15.30(2.40)$ & 0.433 \\
\hline Environment & $16.31(1.93)$ & $16.42(1.77)$ & $16.30(1.85)$ & 0.187 \\
\hline Perception of QOL & $4.30(0.77)$ & $4.40(0.69)$ & $4.39(0.69)$ & 0.332 \\
\hline Health satisfaction & $3.77(0.96)$ & $3.91(0.94)$ & $3.94(1.00)$ & 1.179 \\
\hline SWLS & $28.37(4.89)$ & $28.23(5.47)$ & $28.5 \mathrm{I}(4.67)$ & 0.099 \\
\hline GPM & $22.29(21.86)$ & $23.34(20.97)$ & $21.62(19.72)$ & 0.576 \\
\hline
\end{tabular}

Note: ${ }^{*} p<0.05 ; * *<0.01 ;{ }^{* * *} p<0.00$ I; Superscript letters denote significant differences between groups by Bonferroni post hoc analyses.

Abbreviations: ISI, Insomnia Severity Index; PSQI, Pittsburgh Sleep Quality Index; GAI, Geriatric Anxiety Inventory; GDS, Geriatric Depression Scale; WHOQOL-BREF, World Health Organization Quality of Life-BREF; SWLS, Satisfaction with Life Scale; GPM, Geriatric Pain Measure. 
interval following the intervention was not sufficient for significant changes to be observed compared with the pretest, for all variables considered. Furthermore, no change occurred between the three measurement times concerning level of depression, quality of life, satisfaction with life, and pain.

The lack of improvement in quality of life may be explained by the fact that the participants already evaluated their quality of life very positively at the start of the study, and nearly all of them (95\%) were satisfied with their life. Similarly, at the study onset, most participants reported no or only slight pain.

Participants' level of depression did not decrease significantly by the end of the study. This result can also be explained by the small proportion of participants who presented (mild) symptoms of depression at the study onset, but also by the period during which the study was conducted. In fact, the study began in the summer and ended in late fall. In countries at northern latitudes such as Canada, seasonality is known to exacerbate depressive symptoms and affect sleep quality: the coldest and darkest months are associated with higher rates of depression ${ }^{69}$ and insomnia. ${ }^{70-72}$ This effect is more pronounced in older people than in other age groups. ${ }^{73}$ The present study was probably subject to this seasonality affect. The fact that participants' level of depression did not increase between the start and end of the study therefore reinforces the positive results obtained.

Although positive significant effects were obtained following the intervention, the present research is limited by the absence of a control group. Epidemiological studies conducted at northern latitudes that highlighted increased depression and insomnia when heat and light are replaced by cold and darkness can nonetheless partly compensate for this limitation by constituting a simulated control group. Whereas variables such as medication and use of professional psychological help were controlled, it is possible that factors other than the intervention may have contributed to improving participants' sleep and reducing their anxiety, between the pretest and the two follow-ups. Regression to the mean may, for example, partly explain the results obtained.

The small sample size and some particular participant characteristics may also limit the generalizability of the results. The older people who took part in the study were arguably not fully representative of the population. Their level of education was generally high, and most of them had no chronic diseases, which imply that they represent a privileged group. Further, the participants were comparable to the population of the same age bracket concerning the male-female ratio, marital status, income and body mass index.

\section{Conclusion}

In recent years, literature reviews on the components of the sleep environment have surfaced. The present study is the first to our knowledge to have evaluated the effects of a brief intervention intended to teach elderly people the reasons for and ways to optimize their sleep environment. This type of intervention allows seniors to regain control over their life (empowerment) in order to improve their health and wellness. ${ }^{74}$

The encouraging results obtained from this exploratory study pave the way for similar research on the subject involving a control group and larger samples of older people, which could involve additional analyses to determine the changes to the sleep environment associated with the most beneficial effects. They also invite researchers to evaluate the effects of the intervention on older people who are more disadvantaged, and on people in different age groups. The consideration of sociodemographic characteristics and variables such as measures of motivation and empowerment in future statistical analyses would also provide insight into who could benefit most from such an intervention. It would also be pertinent to perform a longer follow-up in order to get two measurements for each season and to see whether the participants maintain their improvements.

The present study suggests that a brief intervention intended to optimize the sleep environment among the elderly can be a promising alternative or complement to medication or cognitive behavioral therapy, notably owing to its simplicity and the fact that it poses minimal risks, if any. It also meets research goals recently identified by some sleep experts.

\section{Funding}

This research was supported by the Fonds de recherche du Québec - Santé.

\section{Disclosure}

The authors report no potential conflicts of interest in this work. 


\section{References}

1. Ancoli-Israel S, Ayalon L, Salzman C. Sleep in the elderly: normal variations and common sleep disorders. Harvard Rev Psychiatry. 2008;16(5):279-286. doi:10.1080/10673220802432210

2. Subramanian S, Surani S. Sleep disorders in the elderly. Geriatrics. 2007;62(12):10-32.

3. Ohayon MM. Epidemiology of insomnia: what we know and what we still need to learn. Sleep Med Rev. 2002;6(2):97-111. doi:10.1053/ smrv.2002.0186

4. Chaput JP, Yau J, Rao DP, Morin CM. Prevalence of insomnia for Canadians aged 6 to 79. Health Rep. 2018;29(12):16-20.

5. Blackwell T, Yaffe K, Ancoli-Israel S, et al. Poor sleep is associated with impaired cognitive function in older women: the Study of Osteoporotic Fractures. $J$ Gerontol. 2006;61A(4):405-410. doi:10.1093/gerona/61.4.405

6. Jelicic M, Bosma H, Ponds RM, Van Boxtel MJ, Houx PJ, Jolles J. Subjective sleep problems in later life as predictors of cognitive decline. Report from the Maastricht Ageing Study (MAAS). Int J Geriatr Psychiatry. 2002;17(1):73-77. doi:10.1002/gps.529

7. Neikrug AB, Ancoli-Israel S. Sleep disorders in the older adult: a mini-review. Gerontol. 2010;56:181-189. doi:10.1159/000236900

8. Yaffe K, Falvey CM, Hoang T. Connections between sleep and cognition in older adults. Lancet Neurol. 2014;13:1017-1028. doi:10.1016/S1474-4422(14)70172-3

9. Brassington GS, King AC, Bliwise DL. Sleep problems as a risk factor for fall in a sample of community-dwelling adults aged 64-99 years. J Am Geriatr Soc. 2000;48:1234-1240. doi:10.1111/j.15325415.2000.tb02596.x

10. Latimer Hill E, Cumming RG, Lewis R, Carrington S, Le Couteur DG. Sleep disturbances and falls in older people. J Gerontol a Biol Sci Medical Sci. 2007;62(1):62-66. doi:10.1093/gerona/62.1.62

11. Min Y, Slattum PW. Poor sleep and risk of falls in community-dwelling older adults: a systematic review. J Appl Gerontol. 2018;37 (9):1059-1084. doi:10.1177/0733464816681149

12. Stone KL, Ancoli-Israel S, Blackwell T, et al. Actigraphy-measured sleep characteristics and risk of falls in older women. Arch Intern Med. 2008;168(16):1768-1775. doi:10.1001/archinte.168.16.1768

13. Stone KL, Blackwell TL, Ancoli-Israel S, et al. Sleep disturbances and risk of falls in older community-dwelling men: the outcomes of Sleep Disorders in Older Men (MrOS Sleep) Study. $J$ Am Geriatr Soc. 2014;62(2):299-305. doi:10.1111/jgs. 12649

14. Bin YS, Marshall NS, Glozier N. The burden of insomnia on individual function and healthcare consumption in Australia. Aus N Z J Public Health. 2012;36(5):462-468.

15. Silva AA, Mello RGB, Schaan CW, Fuchs FD, Redline S, Fuchs SC. Sleep duration and mortality in the elderly: a systematic review with meta-analysis. BMJ Open. 2016;6(2):e008119. doi:10.1136/bmjopen2015-008119

16. Koffel E, Kroenke K, Bair MJ, Leverty D, Polusny MA, Krebs EE. The bidirectional relationship between sleep complaints and pain: analysis of data from a randomized trial. Health Psychol. 2016;35 (1):41-49. doi:10.1037/hea0000245

17. López-Torres Hidalgo J, Boix Gras C, David García Y, Téllez Lapeira J. Functional status in the elderly with insomnia. Qual Life Res. 2007;16(2):279-286. doi:10.1007/s11136-006-9125-9

18. Baglioni C, Battagliese G, Feige B, et al. Insomnia as a predictor of depression: a meta-analytic evaluation of longitudinal epidemiological studies. J Affect Disord. 2011;135:10-19. doi:10.1016/j.jad.2011.01.011

19. Becker NB, Jesus SN, Kadr J, Viseu JN, Martins RIS. Depression and sleep quality in older adults: a meta-analysis. Psychol Health Med. 2017;22(8):889-895. doi:10.1080/13548506.2016.1274042

20. Foley D, Ancoli-Israel S, Britz P, Walsh J. Sleep disturbances and chronic disease in older adults: results of the 2003 National Sleep Foundation Sleep in America Survey. J Psychosom Res. 2004;56 (5):497-502. doi:10.1016/j.jpsychores.2004.02.010
21. Foley DJ, Monjan AA, Brown SL, Simonsick EM, Wallace RB, Blazer DG. Sleep complaints among elderly persons: an epidemiologic study of three communities. Sleep. 1995;18(6):425-432. doi:10.1093/sleep/18.6.425

22. Gulia KK, Kumar VM. Sleep disorders in the elderly: a growing challenge. Psychogeriatr. 2018;18:155-165. doi:10.1111/psyg.12319

23. Jorm AF, Grayson D, Creasey H, Waite L, Broe GA. Long-term benzodiazepine use by elderly people living in the community. Aust N Z J Public Health. 2000;24(1):7-10. doi:10.1111/j.1467-842X. 2000.tb00715.x

24. Lechevallier-Michel N, Berr C, Fourrier-Réglat A. Incidence and characteristics of benzodiazepine use in an elderly cohort: the EVA study. Therapie. 2005;60(6):561-566. doi:10.2515/therapie:2005078

25. Préville M, Bossé C, Vasiliadis H, et al. Correlates of potentially inappropriate prescriptions of benzodiazepines among older adults: results from the ESA study. Can J Aging. 2012;31(3):313-322. doi:10.1017/S0714980812000232

26. Fick DM, Semla TP, Beizer J, et al. American Geriatrics Society 2015 updated Beers criteria for potentially inappropriate medication use in older adults. J Am Geriatr Soc. 2015;63(11):2227-2246. doi:10.1111/jgs. 13702

27. Tannenbaum C, Diaby V, Singh D, Perreault S, Luc M, Vasiliadis HM. Sedative-hypnotic medicines and falls in community-dwelling older adults: a cost-effectiveness (decision-tree) analysis from a US Medicare perspective. Drugs Aging. 2015;32(4):305-314.

28. Schroeck JL, Ford J, Conway EL, et al. Review of safety and efficacy of sleep medicines in older adults. Clin Ther. 2016;38 (11):2340-2372. doi:10.1016/j.clinthera.2016.09.010

29. Vasiliadis H-M, Dezetter A, Lesage A, Drapeau M. Améliorer l'accès aux psychothérapies au Québec et au Canada: réflexions et expériences de pays francophones [Improving access to psychotherapy in Quebec and Canada: reflections and experiences from Frenchspeaking countries]. Santé mentale au Québec. 2015;40(4):15-30. doi:10.7202/1036090ar

30. Bogner HR, de Vries HF, Maulik PK, Unützer J. Mental health services use: Baltimore Epidemiologic Catchment Area Follow-up. Am J Geriat Psychiatry. 2009;17(8):706-715. doi:10.1097/JGP.0b013e3181aad5c5

31. Wang PS, Lane M, Olfson M, Pincus HA, Wells KB, Kessler RC. Twelve-month use of mental health services in the United States: results from the National Comorbidity Survey Replication. Arch Gen Psychiatry. 2005;62(6):629-640. doi:10.1001/archpsyc.62.6.629

32. Desaulniers J, Desjardins S, Lapierre S, Desgagné A. Sleep environment and insomnia in elderly persons living at home. $J$ Aging Res. 2018;2018:8053696. doi:10.1155/2018/8053696

33. Préville M, Boyer R, Grenier S, et al. The epidemiology of psychiatric disorders in Quebec's older adult population. Can J Psychiatry. 2008;53(12):822-832. doi:10.1177/070674370805301208

34. DuBose JR, Hadi K. Improving inpatient environments to support patient sleep. Int $J$ Qual Health Care. 2016;28(5):540-553. doi:10.1093/intqhe/mzw079

35. Caddick ZA, Gregory K, Arsintescu L, Flynn-Evans EE. A review of the environmental parameters necessary for an optimal sleep environment. Building Environ. 2018;132:11-20. doi:10.1016/j.buildenv.2018.01.020

36. Lillehei AS, Halcon LL. A systematic review of the effect of inhaled essential oils on sleep. J Altern Complement Med. 2014;20 (6):441-451. doi:10.1089/acm.2013.0311

37. Izadi-Avanji FS, Miranzadeh S, Akbari H, Ajorpaz NM, Ahmadi D. Effects of aromatherapy with lavender essential oil on sleep quality among retired older adults. J Res Health. 2019;9(5):437-442. doi:10.29252/jrh.9.5.437

38. Faydalı $\mathrm{S}$, Çetinkaya $\mathrm{F}$. The effect of aromatherapy on sleep quality of elderly people residing in a nursing home. Holist Nurs Pract. 2018;32(1):8-16. doi:10.1097/HNP.0000000000000244

39. Cho EH, Lee MY, Hur MH. The effects of aromatherapy on intensive care unit patients' stress and sleep quality: a nonrandomised controlled trial. Evid Based Complement Alternat Med. 2017;2017: 2856592 . 
40. Karadag E, Samancioglu S, Ozden D, Bakir E. Effects of aromatherapy on sleep quality and anxiety of patients. Nurs Crit Care. 2017;22 (2):105-112. doi:10.1111/nicc. 12198

41. Lai HL, Good M. Music improves sleep quality in older adults. $J$ Ad Nurs. 2006;53(1):134-146. doi:10.1111/j.1365-2648.2006.03693.x

42. de Niet G, Tiemens B, Lendemeijer B, Hutschemaekers G. Musicassisted relaxation to improve sleep quality: meta-analysis. $J A d v$ Nurs. 2009;65(7):1356-1364. doi:10.1111/j.1365-2648.2009.04982.x

43. Chang E-T, Lai H-L, Chen P-W, Hsieh Y-M, Lee L-H. The effects of music on the sleep quality of adults with chronic insomnia using evidence from polysomnographic and self-reported analysis: a randomized control trial. Int J Nurs Stud. 2012;49(8):921-930. doi:10.1016/j.ijnurstu.2012.02.019

44. Wang Q, Chair SY, Wong EML, Li X. The effects of music intervention on sleep quality in community-dwelling elderly. $J$ Alt Complement Med. 2016;22(7):576-584. doi:10.1089/acm.2015.0304

45. Haghayegh S, Khoshnevis S, Smolensky MH, Diller KR, Castriotta RJ. Before-bedtime passive body heating by warm shower or bath to improve sleep: a systematic review and meta-analysis. Sleep Med Rev. 2019;46:124-135. doi:10.1016/j.smrv.2019.04.008

46. Irish LA, Kline CE, Gunn HE, Buysse DJ, Hall MH. The role of sleep hygiene in promoting public health: a review of empirical evidence. Sleep Med Rev. 2015;22:23-36. doi:10.1016/j.smrv.2014. 10.001

47. Folstein MF, Folstein S, McHugh PR. Mini-Mental State: a practical method of grading the cognitive state of patients for the clinician. J Psychiatr Res. 1975;12:189-198. doi:10.1016/0022-3956(75)90026-6

48. Morin CM. Insomnia: Psychological Assessment and Management. New York: Guilford; 1993.

49. Morin CM, Belleville G, Bélanger L, Ivers H. The Insomnia Severity Index: psychometric indicators to detect insomnia cases and evaluate treatment response. Sleep. 2011;34:601-608. doi:10.1093/sleep/ 34.5.601

50. Bastien $\mathrm{CH}$, Vallières $\mathrm{A}$, Morin $\mathrm{CM}$. Validation of the Insomnia Severity Index as an outcome measure for insomnia research. Sleep Med. 2001;2:297-307. doi:10.1016/S1389-9457(00)00065-4

51. Buysse DJ, Reynolds CF 3rd, Monk TH, Berman SR, Kupfer DJ. The Pittsburgh Sleep Quality Index: a new instrument for psychiatric practice and research. Psychiatry Res. 1989;28(2):193-213. doi:10.1016/0165-1781(89)90047-4

52. Blais FC, Gendron L, Mimeault V, Morin CM. Évaluation de 1'insomnie: validation de trois questionnaires [Assessment of insomnia: validation of three questionnaires]. Encephale. 1997;23(6):447-453.

53. Pachana NA, Byrne GJ, Siddle H, Koloski N, Harley E, Arnold E. Development and validation of the Geriatric Anxiety Inventory. Int Psychogeriatr. 2007;19(1):103-114. doi:10.1017/S10416102060 03504

54. Johnco C, Knight A, Tadic D, Wuthrich VM. Psychometric properties of the Geriatric Anxiety Inventory (GAI) and its short-form (GAI-SF) in a clinical and non-clinical sample of older adults. Int Psychogeriat. 2015;27(7):1089-1097. doi:10.1017/S1041610214001586

55. Champagne A, Landreville P, Gosselin P, Carmichael PH. Psychometric properties of the French Canadian version of the Geriatric Anxiety Inventory. Aging Ment Health. 2018;22(1):40-45. doi:10.1080/13607863.2016.1226767

56. Yesavage JA, Brink TL, Rose TL, et al. Development and validation of a geriatric depression screening scale: a preliminary report. J Psychiatr Res. 1982;17:37-49. doi:10.1016/0022-3956(82)90033-4

57. Yesavage JA. Geriatric Depression Scale. Psychopharmacol Bull. 1988;24:709-711.
58. Bourque P, Blanchard L, Vézina J. Étude psychométrique de l'Échelle de dépression gériatrique [Psychometric study of the Geriatric Depression Scale]. Can J Aging. 1990;9(4):348-355. doi:10.1017/S0714980800007467

59. Laprise R, Vézina J. Diagnostic performance of the Geriatric Depression Scale and the Beck Depression Inventory with nursing home residents. Can J Aging. 1998;17(4):401-413. doi:10.1017/ S0714980800012678

60. World Health Organization. Division of Mental Health. WHOQOL$B R E F$ : introduction, administration, scoring and generic version of the assessment. Field trial version; December 1996. Available from: https://apps.who.int/iris/handle/10665/63529. Accessed August 7, 2020.

61. Skevington SM, Lotfy M, O'Connell KA. The World Health Organization's WHOQOL-BREF quality of life assessment: psychometric properties and results of the international field trial. A report from the WHOQOL group. Qual Life Res. 2004;13:299-310. doi:10.1023/B:QURE.0000018486.91360.00

62. Leplège A, Réveillère C, Ecosse E, Caria A, Rivière H. Propriétés psychométriques d'un nouvel instrument d'évaluation de la qualité de vie, le WHOQOL-26, à partir d'une population de malades neuro-musculaires [Psychometric properties of a new instrument for evaluating quality of life, the WHOQOL-26, in a population of patients with neuromuscular diseases]. Encephale. 2000;26 (5):13-22.

63. Diener ED, Emmons RA, Larsen RJ, Griffin S. The Satisfaction with Life Scale. J Pers Assess. 1985;49:71-75. doi:10.1207/s15327 752jpa4901_13

64. Pavot W, Diener E. Review of the Satisfaction with Life Scale. Psychol Assess. 1993;5:164-172. doi:10.1037/1040-3590.5.2.164

65. Blais MR, Vallerand RJ, Pelletier LG, Brière NM. L'échelle de satisfaction de vie: validation canadienne-française du "Satisfaction with Life Scale." [The life satisfaction scale: French-Canadian validation of the Satisfaction with Life Scale]. Can J Behav Sci. 1989;21 (2):210-223. doi:10.1037/h0079854

66. Ferrell BA, Stein WM, Beck JC. The Geriatric Pain Measure: validity, reliability and factor analysis. $J \mathrm{Am}$ Geriatr Soc. 2000;48:1669-1673. doi:10.1111/j.1532-5415.2000.tb03881.x

67. Richardson JTE. Eta squared and partial eta squared as measurements of effect size in educational research. Educ Res Rev. 2011;6:135-147. doi:10.1016/j.edurev.2010.12.001

68. Cohen J. Statistical Power Analysis for the Behavioural Sciences. New York: Academic Press; 1969:pp. 287-280.

69. Patten SB, Williams JVA, Lavorato DH, et al. Seasonal variation in major depressive episode prevalence in Canada. Epidemiol Psychiatr Sci. 2017;26(2):169-176. doi:10.1017/S2045796015001183

70. Husby R, Lingjaerde O. Prevalence of reported sleeplessness in northern Norway in relation to sex, age and season. Acta Psychiatr Scand. 1990;81:542-547. doi:10.1111/j.16000447.1990.tb05009.x

71. Johnsen MT, Wynn R, Bratlid T. Is there a negative impact of winter on mental distress and sleeping problems in the subarctic: the Tromso Study. BMC Psychiatry. 2012;12:225.

72. Pallesen S, Nordhus IH, Nielsen GH, et al. Prevalence of insomnia in the adult Norwegian population. Sleep. 2001;24:771-779.

73. Suzuki M, Taniguchi T, Furihata R, et al. Seasonal changes in sleep duration and sleep problems: a prospective study in Japanese community residents. PLoS One. 2019;4(4):e0215345. doi:10.1371/journal.pone. 0215345

74. Shearer NB. Health empowerment theory as a guide for practice. Geriatr Nurs. 2009;30(2):4-10. 


\section{Publish your work in this journal}

Clinical Interventions in Aging is an international, peer-reviewed journal focusing on evidence-based reports on the value or lack thereof of treatments intended to prevent or delay the onset of maladaptive correlates of aging in human beings. This journal is indexed on PubMed Central, MedLine, CAS, Scopus and the Elsevier
Bibliographic databases. The manuscript management system is completely online and includes a very quick and fair peer-review system, which is all easy to use. Visit http://www.dovepress.com/ testimonials.php to read real quotes from published authors.

Submit your manuscript here: https://www.dovepress.com/clinical-interventions-in-aging-journal 